\title{
Pre-treatment of Stored Dry Seeds of Aframomum melegueta in-vitro
}

\section{Tsombou FM ${ }^{1}$, Anjah $\mathrm{GM}^{1 *}$, Antoine Mvondo $\mathrm{Ze}^{2}$}

\author{
${ }^{1}$ Dept. of Plant Biology, University of Dschang, P.O. Box 67 Dschang, Cameroon. \\ ${ }^{2}$ Dept. of Soil Science, University of Dschang, P.O. Box 222, Dschang, Cameroon.
}

Article No.: 032316068

DOI: 10.15580/GJAS.2016.4.032316068

Submitted: $23 / 03 / 2016$

Accepted: 06/04/2016

Published: 25/04/2016

*Corresponding Author

Anjah GM

E-mail: ngracemendi@yahoo

.$c 0 m$

\section{Keywords:}

Conservation, Germination, Non

Wood Forest Products,

Silvilculture, Pre-treatments
Background: The increase in the value of NTFPs concerns: seeds, fruits, edible vegetable, mushrooms, fish and game. Of these NWFPs, Aframomum species among which is $A$. melegueta (Jujube), a herbaceous, perennial classified in the family Zingiberaceae, class Monocotyledonae is over harvested in the wild.

Methods: This study was conducted with a view to maximize the germination of seeds of Aframomum melegueta and eliminate the obstacle of integumentary inhibition after a month of storage of these seeds. Physical pre-treatments were done using three methods which included the steeping of seeds in cold tap water at 24, 48 and 72 hours respectively, soaking the seeds in boiling water for 5,10 and 15 minutes, and chemical application by soaking the seeds in sulphuric acid at 20, 40 and 60 minutes respectively before being placed in the germination Petri dishes. The optimal conditions for germination of the seeds were determined which included the speed of germination, germination percentage and seeds latency. The data collected were submitted to the Duncan test at $5 \%$ significance threshold.

Results: The results indicated that pre-treatment with sulphuric acid diluted to $50 \%$ significantly improved the germination of A.melegueta seeds. This pretreatment resulted in a $\mathbf{1 0 0}$ percent germination of seeds. The latency period was significantly shorter (6 days) obtained against $\mathbf{5 0}$ days in the control group. The seed germination rate with this pre-treatment was 2.2 grains/day against 0.3 rains/day in the control group. Other pre-treatments such as cold tap water and boiling water had no significant effect on the germination of these seeds.

Conclusion: At the end of the experiment, it was observed that chemical pretreatment on dry seeds of $A$. melengueta was the best.

\section{LIST OF ABBREVATIONS}

NTFPs: Non-Timber-Forest Products MINFWL: Ministry of Forestry and Wildlife 


\section{INTRODUCTION}

The forest is a living environment maintained by the interactions between the biotic and abiotic components (Broekhoven, 1996). Forests provide various services to human communities through non-timber forest products (NTFPs). According to FAO (2005), NTFPs are exploited in four billion hectares of forest on 30\% of land and the value of wood extracted declines i.e. $\$$ 64 billion while the value of NTFPs increases steadily by 4.7 billion dollars. The increase in the value of NTFPs concerns: seeds, fruits, edible vegetable, mushrooms, fish and game. Of these NWFPs, Aframomum species among which is A. melegueta (Jujube), a herbaceous, perennial classified in the family Zingiberaceae, class Monocotyledonae. The leaves are simple and asymmetrical with a membranous ligule. The inflorescences are born at the base of the stem with reddish bracts. The fruit is a bright red berry at maturity. It is indehiscent with seeds enclosed in a white pulp. This species is found in Guinea, Nigeria, Gabon, and Cameroon where they are found in the Western Highlands in specific sacred forests (Anjah et al., 2015) especially its fruit for food, medicinal and cultural purposes. A. melegueta in Guinea is ranked among the $2^{\text {nd }}$ category endangered plant species (Diawara 2000). In 2007 in Cameroon, MINFWL classified the species among special products. Culturally, the fruits of $A$. melegueta are used during the enthronement of chiefs and upon succession, in the rites of blessing and protection in traditional medicine to cure diseases. Aframomum species is food for man, monkeys and some rodents. The fruits are exported and sold on international markets (Yembi, 2000). The price of the fruit varies between 50 and 100 CFA per unit while a $50 \mathrm{~kg}$ bag costs between 14,000 and 20,000 CFA francs (Tabuna, 1999). Thus, the marketing of these NTFPs generates revenues that are intended for household economy. Ecologically, species of Aframomum are important for soil conservation through their rhizomes and large leaves that protect soils against erosion (Eyob et al., 2008). Thus it contributes to the carbon sink and to the fight against climate change affecting the globe increasingly.

Documentation on seed pre-treatment methods of most NTFPs is rare and that on Aframomum species is non-existent. The dry seeds of Aframomum melegueta are difficult to germinate. Amponsah et al. (2012), showed through their work that it is due to seed coat dormancy. Similarly, Tsombou et al. (2015) found during their work on dried stored seeds that they gradually lose their ability to germinate on storage. In the wild, there is a sharp decline of its populations as observed by Anjah et al. (2015).

Methods of pre-treatment of the dried seeds of A. melegueta are very limited, the reason why this work was conducted with a view to apprehend the best pre-treatment for the dried stored seeds of $A$. melegueta.

\section{MATERIALS AND METHODS}

This study was conducted at the University of Dschang (Cameroon). The University of Dschang is located at $1,345 \mathrm{~m}$ altitude $26^{\prime} 38^{\prime \prime}$ and $5^{\circ}$ north latitude and $10^{\circ}$ $03^{\prime} 11$ to 'East Longitude (Fig. 1). The Soil and Environmental Chemistry Laboratory and the Botany and Applied Plant Biology Laboratory, all of the University of Dschang were used for the different phases of this work.

For germination, the plant materials consisted of the dry seeds extracted from fruits of $A$. melegueta collected from populations in the Western Highlands of Cameroon (Fig. 2). 


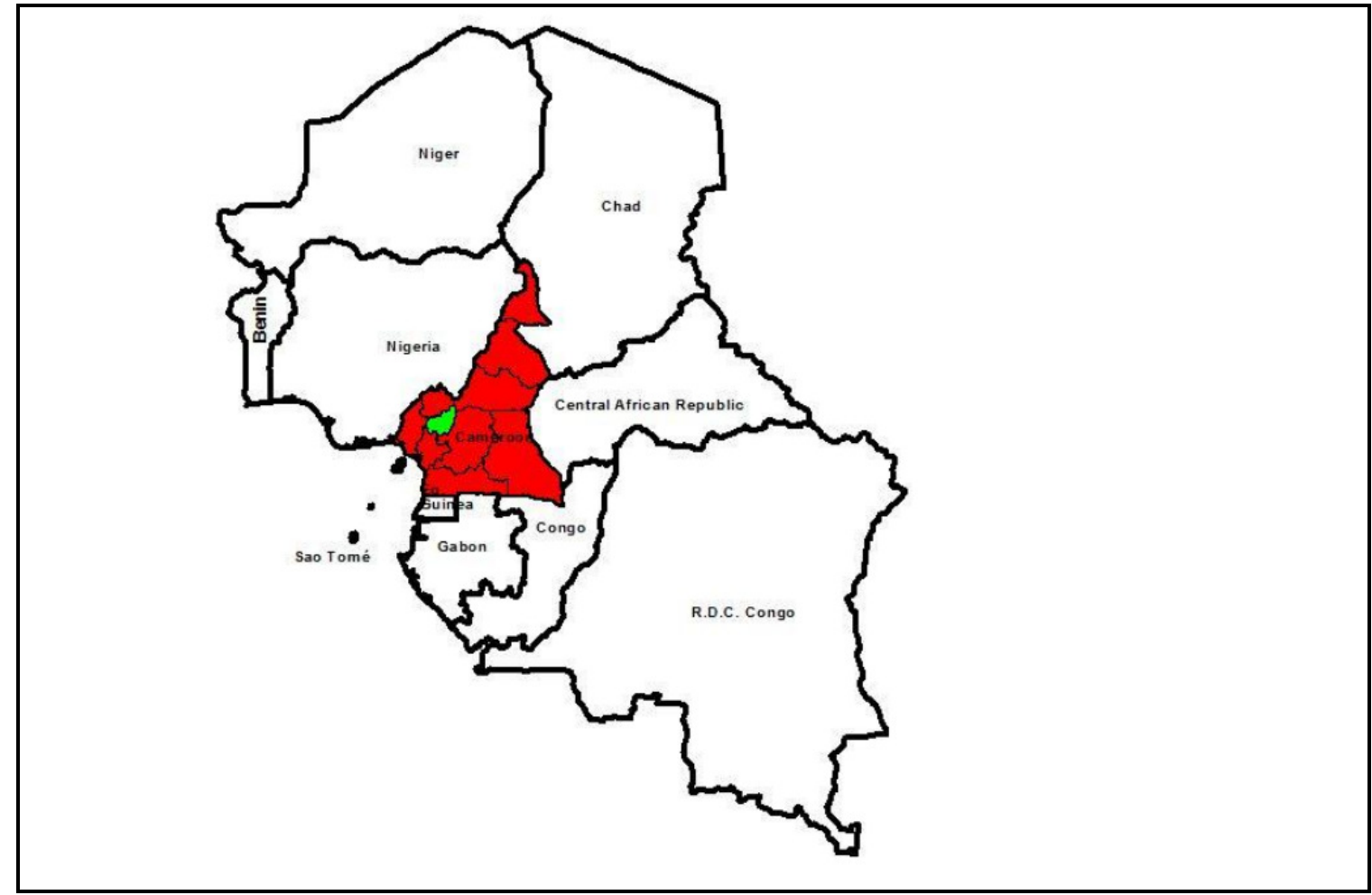

Figure 1: Location map of the study area in West and Central Africa.

Sources: Administrative maps of Cameroon, MOTHERS ISH Centre National Geographic, Yaoundé, 1984-Lifting GPS, September 2006, April 2007 and GARMIN Database 2003.

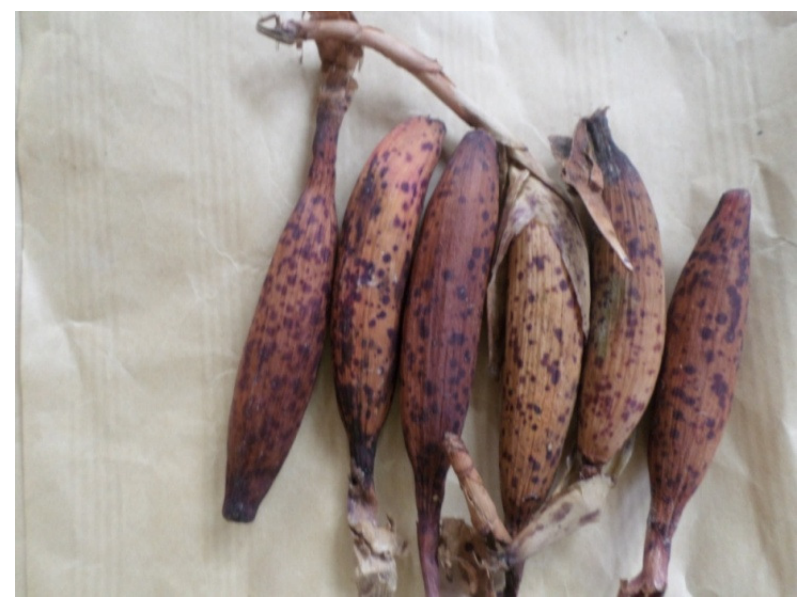

Figure 2: Dried fruits of Aframomum melegueta

\section{Pre-treatment Experiments}

A viability test to estimate the percentage of good seeds in a seed lot was carried out. Wamegni (1991) viability method was adopted in which water at ambient temperature was used as a release agent. The seeds of $A$. melegueta were soaked in a container of water for 5 days. Seeds that floated were not viable while those immersed in the bottom of the container were viable. The seeds were dried in an oven at a temperature of $60{ }^{\circ} \mathrm{C}$, transferred into a glass jar and stored for one month.
Some of the different pre-treatment methods were adopted from Aronu et al. (2010) with some modifications. A total of 1,320 seeds were used. There were three pre-treatments (cold tap water, boiling water and $50 \%$ sulphuric acid). 132 seeds were used as control. In the first pretreatment, 132 seeds were dipped in cold tap water for 24 hours (T1), 132 seeds dipped in cold tap water for 48 hours (T2), and 132 seeds were dipped in cold tap water for 72 hours (T3). The second pretreatment was that of hot water with 132 seeds soaked in boiling hot water for 5 mins (T4), 132 seeds soaked in boiling hot water for 10 mins (T5), and 132 seeds were soaked in boiling hot water for 15 
mins (T6). For the third pre-treatment comprising soaking of the seeds in $50 \%$ sulphuric acid, 132 seeds were soaked in dilute sulphuric acid at $50 \%\left(\mathrm{H}_{2} \mathrm{SO} 4\right)$ for $20 \mathrm{~min}(\mathrm{~T} 7), 132$ seeds soaked in at $50 \%\left(\mathrm{H}_{2} \mathrm{SO}_{4}\right)$ for $40 \mathrm{~min}$ (T8), and 132 seeds soaked in dilute sulphuric acid at $50 \%\left(\mathrm{H}_{2} \mathrm{SO}_{4}\right)$ for $60 \mathrm{~min}$ (T9). After the various pre-treatments, the seeds were placed in Petri dishes and laid out in groups of 04 depending on the treatment and each having three replicates. They were sprayed with water daily.

Data collection on germination parameters were carried out every 2 days from the first day of planting. The following were determined: the percentage germination, germination latency and speed of seed germination. The seed germination rate (GR): $\mathrm{GR}=\mathrm{G} 1 / \mathrm{G} 2+\mathrm{T} 1 / \mathrm{T} 2+(\mathrm{G} 3) / \mathrm{T} 3+\mathrm{Gn} / \mathrm{Tn}$, Keshava (2014) Where G1 = Number of seeds germinated on the first day; G2 = Number of seeds germinated the second day; G3 = Number of seeds germinated on the third day; Day $1=\mathrm{T} 1$, Day $2=\mathrm{T} 2$ and Day $3=$ T3. Latency period adapted from Ahoton et al. (2009). Germination percentage (GP): $\mathrm{GP}=\mathrm{Ng} /$ NT $\times 100$ (Niang-Diop et al., 2010) Where $\mathrm{Ng}=$ number of germinated seeds, and NT= Total number of seeds. The data collected were subjected to analysis of variance using SPSS version 17.0 software. The Duncan test made it possible to separate means at $5 \%$ significance level.

\section{RESULTS}

Seed germination parameters of dry seeds of Aframomum melegueta stored for one month and having undergone different pre-treatments (cold tap water, boiling water and sulphuric acid diluted for 50 $\%)$ started germinating six (06) days after planting. Figure 3 shows the stages of seed germination of Aframomum melegueta pre-treatment with sulphuric acid diluted to $50 \%$ while seed germination of $A$. melegueta in the culture medium with boiling water is shown in Figure 4.

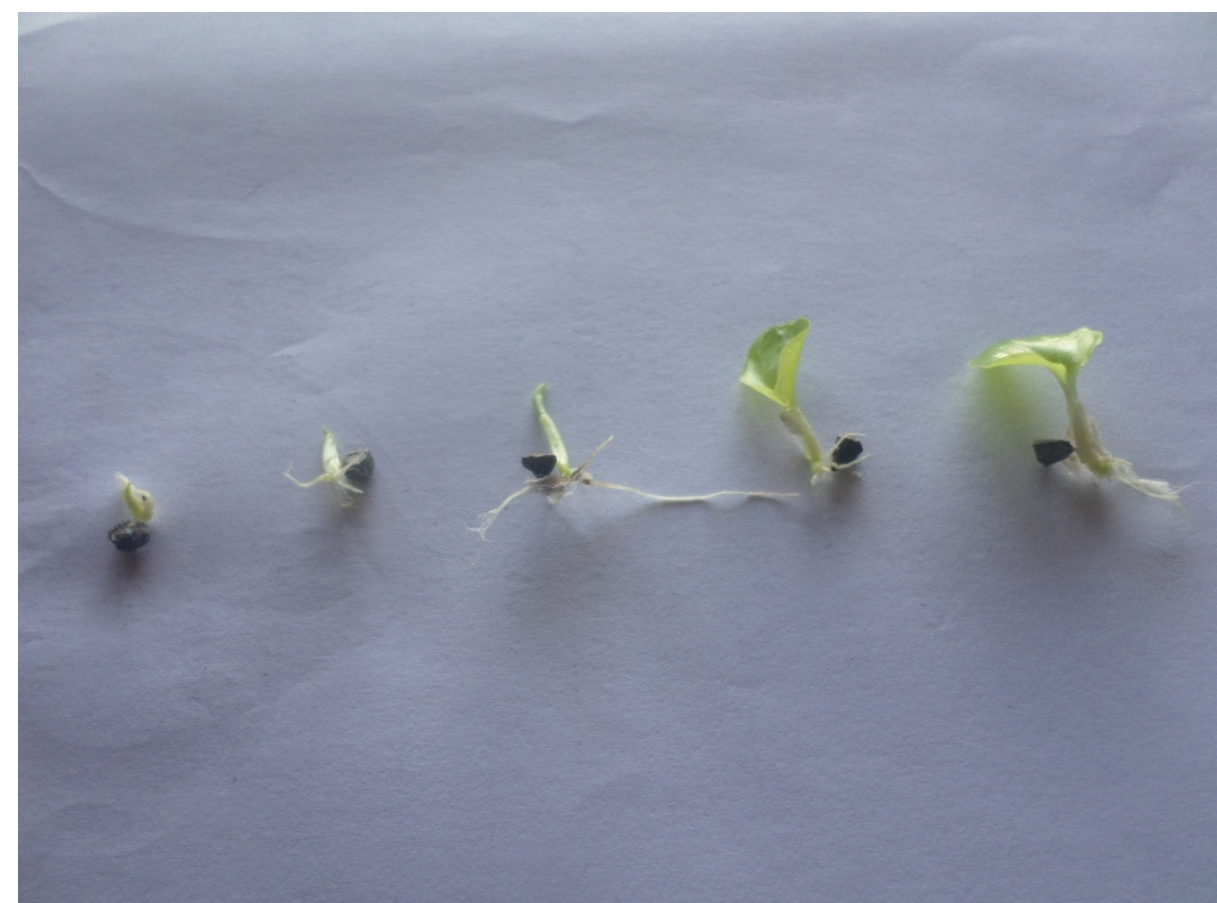

Figure 3: Stages of seed germination of Aframomum melegueta pre-treatment with sulphuric acid diluted to $50 \%$ 


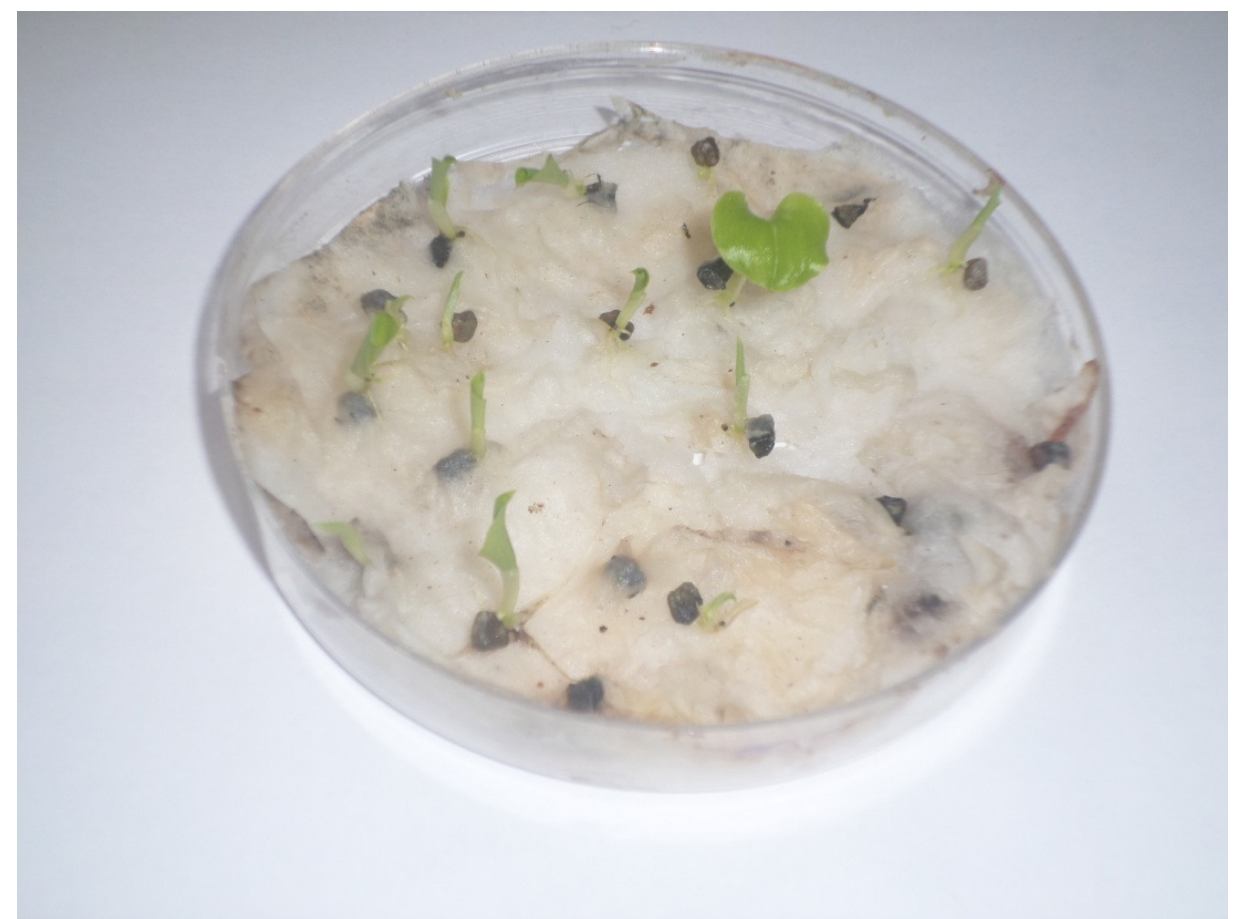

Figure 4: Seed germination of $A$. melegueta in the boiling water medium

\section{Percentage of seed germination}

After 60 days of applying the different pre-treatments, the seed germination percentage varied from 30.3 to $60.61 \%$ for the pretreated seeds with cold tap water. Compared to the control group, no significant difference was observed in this group. During this, the highest percentage of seeds that germinated was for those that had been soaked in cold T3 for 72 hours $(60.61 \%)$ and lowest was in the control group $(7.58 \%)$. For the seeds pretreated with boiling water, germination percentage ranged from 32.57 to $78.79 \%$, and no significant difference was observed in this group. However, the seeds that were soaked in boiling water for 5 minutes showed a significant high germination percentage (78.79\%) compared with seeds which had been soaked in hot boiling water for 15 minutes $(32.57 \%)$ and lowest in the control $(7.58 \%)$. Seeds soaked in sulphuric acid $50 \%$ showed germination percentages ranging from 55.61 to $100 \%$. Significant values $(P \leq 0.05)$ were observed in the soaked seeds respectively for 20 minutes in sulphuric acid at $50 \%$ compared to the control group showed no significant difference.

In general, seeds pretreated with sulphuric acid showed significantly higher germination percentages $(100 \%)(P \leq 0.05)$ compared to treatment with the cold tap water, boiling water and the control group $(7.58 \%)$. The percentage of germination of Aframomum melegueta treatments is shown in Table 1.

Table 1: Percentage of seed germination of Aframomum melegueta treatments

\begin{tabular}{cc}
\hline Treatments & \% of germination \\
\hline T1 & $30.3 \pm 17.32^{\mathrm{e}}$ \\
T2 & $33.33 \pm 15.84^{\mathrm{e}}$ \\
T3 & $60.61 \pm 12.37^{\mathrm{a}}$ \\
T4 & $78.79 \pm 16.22^{\mathrm{bc}}$ \\
T5 & $66.67 \pm 10.78^{\mathrm{ca}}$ \\
T6 & $32.57 \pm 2.9^{\mathrm{e}}$ \\
T7 & $100 \pm 0^{\mathrm{a}}$ \\
T8 & $85.24 \pm 1,52^{\mathrm{ab}}$ \\
T9PH & $55.61 \pm 7.16^{\mathrm{de}}$ \\
Control & $7.58 \pm 3.91^{\mathrm{T}}$ \\
\hline${ }^{*}$ Average \pm standard deviation followed by the same superscript letters in columns are not \\
significantly different according to Duncan test $(\mathrm{P} \leq 0.05)$
\end{tabular}




\section{Germination rate}

The GR was not significantly different $(P \leq 0.05)$ for the seeds soaked in tap water compared with the control group. The values of the seed germination rates pretreated with tap water $(24 \mathrm{~h}, 48 \mathrm{~h}$ and $72 \mathrm{~h})$ were 0.67-0.73-1.34 seeds per day respectively. The highest value was obtained for those soaked for 72 hours and lowest in the control group ( 0.3 seeds per day). For the boiling water treatment $(5,10$ and 15 $\mathrm{min})$, the germination rates were 1.73-1.47-0.72 seeds per day respectively. Compared with the control group, no significant differences $(P \leq 0.05)$ were observed in these treatments. However, the highest value was obtained in the seeds pretreated for 5 minutes $(1.73$ seeds per day) and lowest in the control $(0.3$ seed / day). The values 2.2, 2.01 and 1.5 seeds per day respectively were obtained for seeds pretreated with sulphuric acid for 20, 40 and $60 \mathrm{~min}$. The seed treatments in 50\% sulphuric acid for 20 and 40 minutes showed significant differences ( $P \leq 0.05)$ compared to the control group ( 0.3 seeds / day). Overall, the use of sulphuric acid as a pretreatment of the seeds showed significant differences at $(P \leq 0.05)$ on the germination rate compared to treatment with the tap water, boiling water and the control group. Table 2 shows the Germination rate of seed of Aframomum melegueta treatments.

Table 2: Germination rate of seed of Aframomum melegueta treatments

\begin{tabular}{cc}
\hline Treatments & Germination rate / days \\
\hline T1 & $0.67 \pm 0.12^{\mathrm{a}}$ \\
T2 & $0.73 \pm 0.09^{\mathrm{a}}$ \\
T3 & $1.34 \pm 0.12^{\mathrm{c}}$ \\
T4 & $1.73 \pm 0.09^{\mathrm{D}}$ \\
T5 & $1.47 \pm 0.19^{\mathrm{c}}$ \\
T6 & $0.72 \pm 0.07^{\mathrm{a}}$ \\
T7 & $2.2 \pm 0.04^{\mathrm{a}}$ \\
T8 & $2.01 \pm 0.02^{\mathrm{a}}$ \\
T9 & $1.5 \pm 0.07^{\mathrm{D}}$ \\
Control & $0.3 \pm 0.66^{\mathrm{e}}$ \\
\hline
\end{tabular}

${ }^{*}$ Average \pm standard deviation followed by the same superscript letters in columns are not significantly different according to Duncan test $(P \leq 0.05)$

\section{Latency period}

Mean values for latency period showed no significant differences $(P \leq 0.05)$ in the tap water treatments compared to the control group. The values were respectively $21,19,15$ and 50 days for treatment with tap water (24, 48 and 72 hours) and for the control. It was shorter for the treatment of 72 hours (15 days) and longer in the control group (50 days). In the treatment with boiling water $(5,10$ and $15 \mathrm{~min})$ no significant difference $(P \leq 0.05)$ was observed compared to the control group showed a significant difference $(P \leq 0.05)$. The latency values obtained in this group and in the control group were respectively 13, 15, 19 and 50 days. Treating seeds with boiling water showed no significant difference $(P \leq 0.05)$ but reduced the 13-day lag time compared to the control group where this time was longer (50 days). Seed treatment with sulphuric acid for 20, 40 and $60 \mathrm{~min}$ were respectively 6,7 and 10 days and these values showed no significant difference $(P \leq 0.05)$ compared to control group that had a latency time (50 days) significantly different $(P \leq 0.05)$. However, this time was shorter for seeds treated with sulphuric acid (6 days) compared to the control group where this time was longer (50 days). In short, ten treatments for the control group had a significantly long latency period (50 days) compared to treatment with tap water, boiled water and $50 \%$ sulphuric acid which did not show a significant difference. But of all treatments including the control treatment in $50 \%$ sulphuric acid had the shortest latency period (06 days). The germination of latency of seeds from $A$. melegueta by treatments is shown in Table 3. 
Table 3: Germination of latency of seeds from $A$. melegueta by treatments

\begin{tabular}{cc}
\hline Treatments & Latency time \\
\hline T1 & $21 \pm 1.41^{\mathrm{b}}$ \\
T2 & $19 \pm 2.83^{\mathrm{bc}}$ \\
T3 & $15 \pm 7.07^{\mathrm{bcd}}$ \\
T4 & $13 \pm 2.12^{\mathrm{bcd}}$ \\
T5 & $15 \pm 3.54^{\mathrm{bcd}}$ \\
T6 & $19 \pm 1.41^{1 \mathrm{cc}}$ \\
T7 & $6 \pm 1.41^{\mathrm{d}}$ \\
T8 & $7 \pm 2.83^{\mathrm{d}}$ \\
T9 & $10 \pm 4.24^{\mathrm{cd}}$ \\
Control & $50 \pm 7.07^{\mathrm{a}}$ \\
\hline${ }^{*}$ Average \pm standard deviation followed by the same superscript letters in columns \\
are not significantly different according to Duncan test $(P \leq 0.05)$
\end{tabular}

\section{DISCUSSION}

It was observed that values obtained on the effects of pre-treatments and germination corresponded with those observed by other authors. For example, soaking dry seeds of $A$. melegueta in sulphuric acid 5 $0 \%$ for 20 min positively influenced the latency period, the germination rate and the percent germination of seeds of other NFTPs (Niang-Diop et al., 2010). They observed that the germination capacity of seeds of Prosopis africana when soaked in sulphuric acid increased. Thus, in this experiment the percentage of germination of $A$. melegueta soaked in sulphuric acid $50 \%$ for 20 minutes was significantly higher compared to those obtained from cold tap water, boiling water and the control. Also the germination latency period was significantly shorter (06 days) and the highest speed of germination (2.2 seeds per day). The work of Eyob (2009) and Amponsah et al. (2012) respectively with $A$. corrorima and $A$. melegueta confirm this same observation.

Although Jaouadi et al. (2010) observed the positive effect of sulphuric acid on the dormancy of seeds, the time the seeds were soaked in this pretreatment needs to be well defined to avoid denaturing. Soaking the seeds for one hour in sulphuric acid at $50 \%$ in this study did not give a significantly high germination percentage of seed germination. The seed germination percentage, the germination speed and the latency period of Aframomum melegueta were not significantly elevated in the group of seeds soaked in boiling water and in the control group. However, the seeds soaked in boiling water for 5 minutes showed a higher germination percentage $(78.79 \%)$, followed by the seed soaked in boiling water for $10 \mathrm{~min}(66.67 \%)$ and the those in boiling water for 15 minutes which was the lowest (32.57\%). Similarly, the results of the germination latency showed that seeds soaked in boiling water respectively for 5,10 and 15 min with 13 , 15 and 19 days suggests that the temperature would affect the dormancy of seed of $A$. meleguta compared to the control group which showed a latency time of 50 days. In reality, these germination latency values become longer with the increase in temperature and are shortened when the temperature decreases. Increasing the temperature would progressively inhibit the germination of these seeds. The same observation is made on the rate of germination of dry seeds of $A$. melegueta because it accelerated when the temperature decreased and decreased as the temperature increased. Fawa (2014), showed that inadequate temperature on the dormancy of seeds influences its germination capacity. The same observation is seen in Fawa (2014) work on the dormancy of Leuceana lanceolata seeds. He also noticed that the germination of some seeds of this plant species was inhibited in boiling water. Soaking the seeds in plain tap water for 24,48 or 72 hours according to Nunez and Calvo (2000) is one of the best pre-treatments because it provides good results on the seed germination. But this does not seem to be the case with Aframomum melegueta because this treatment did not produce significantly higher results compared with the sulphuric acid treatment. Nevertheless, the results obtained in the control group reveal that more time soaking in cold tap water is needed, hence, the longer the latency period, the higher the rate of germination. The soaking time of these seeds in tap water for 24, 48 and 72 hours during this study would have been insufficient to soften the seed coats of such seeds.

\section{CONCLUSION}

The behaviour of dry seeds of Aframomum melegueta varies depending on the type of pre-treatment. Soaking the seeds for 20 minutes in sulphuric acid at $50 \%$ improves the germination percentage $(100 \%)$, the germination latency is shorter (06 days), and the seed germination rate is increased ( 2.2 seeds per day). This pre-treatment may be recommended to local populations and nurseries because it is inexpensive and simple to perform.

\section{COMPETING INTERESTS}

The authors have declared no competing interest

\section{AUTHORS' CONTRIBUTIONS}

Tsombou FM and Anjah GM carried out the work on the field under the supervision of Antoine Mvondo Ze. 
The corresponding author, Anjah G. M., designed the experiment, tested the different treatments on cold tap water and boiling water, and collected data on these. This author single-handedly formatted the paper according to the Greener Journal instructions to author.

Tsombou FM carried out the treatment with sulphuric, collected the data and analyzed the results.

\section{ACKNOWLEDGEMENTS}

We are grateful to the Department of Plant Biology in the University of Dschang, Cameroon for provision of space and facilities in the Laboratory for this study. Their Financial, technical assistance and guidance is appreciated.

\section{REFERENCES}

Ahoton LE, Adgakpa BG, M'poFontiM'po and Akpo LE (2009). Effets des prétraitements des semences sur la germination de Prosopis africana (Caesalpianceae). Tropicultura. 4. Pp. 233-238.

Amponsah J, Danso K and Elegba W (2012). Enhancing germination of Aframomum melegueta $\mathrm{K}$. Schum.through Ex-vitro and In-vitro Propagation Techniques.Resilience of agricultural systems against crises. Ghana. 10p.

Anjah GM, Nguetsop VF, Tsombou FM and Njoya MT (2015). Effect of field capacity of sacred forest soils on regeneration of Aframomum melegueta on Western Highlands in Cameroon. Journal of Horticulture and Forestry 7 (5): 142-148.

Aronu AJ, Nwachukwu OC and Adebayo O (2010). The effect of pre-treatments on germination of seeds of Aframomum melegueta in southern Nigeria. Forestry Research Institute of Nigeria, Eastern Research Station, Umuahia, Abia State, Nigeria. Journal of Environmental Issues and Agriculture in Developing Countries 2 (1): 6-12

Broekhoven G (1996). Non -timber forest products: ecological and economic aspects of exploitation in Colombia, Ecuador and Bolivia IUCN, Gland, Suisse et Cambridge, Royaume-Uni. Pp. 30.

Diawara D (2000). Les données statistiques sur les produits forestiers non-ligneux en république de Guinée. Collecte et analyse de données pour l'aménagement durable des Forêts - joindre les efforts nationaux et internationaux. Programme de partenariat CE-FAO (1998-2001). Ligne budgétaire forêt tropicale B7-6201/97-15/VIII/FOR projet GCP/INT/679/EC. Pp.32.

Eyob S, Appelgren M, Rohloff G, Tsegaye A and Messele G (2008). Traditional and Medecinal uses of essential oil composition of leaves and rhizomes of Aframomum corrima.Gansen Sourthern Ethiopia. Science Africa Global Botanic 74: 181185.

Eyob S (2009). Promotion of seed germination, subsequent seedling growth and in vitro propagation of korima Aframomum corrorima. Journal of Medicinal Plants Research. 3(9) : 652659.

FAO (2005). Communiqué " la déforestation se poursuit à un rythme alarmant- Nouveau Chiffres de la FAO sur les forêts mondiales " Rome. Pp. 2.

Fawa G (2014). Phénologie et modes de propagation de quatre essences agroforestières locales dans les hautes savanes guinéennes (Adamaoua, Cameroun). Thèse de Doctorat/ Ph.D. Université de Ngaounderé. Pp. 210.

Jaouadi W, Hamrouni L, Souayeh N and Khouja LM (2010). Etude de la germination des grains d'Acacia tortilis sous différentes contraintes abiotiques. Biotechnol.Agron. Soc. Environ. 14 (4): 643- 652

Keshava CK, Krishnakumar G and Shenoy HS (2014). Seed germination studies on lophopetalumwightianumarn. - An evergreen species of the Western Ghats. International Journal of Plant, Animal and Environmental Sciences. 4(3) : 502-507.

Niang-Diop F, Sambou B and Lykkem A (2010). Contraintes de régénération naturelle de Prosopis africana: facteurs affectant la germination des graines. Institut des Sciences Anta Diop. BP: 5005. Dakar Fanna, Sénégal. 4 (5). Pp. 16931705.

Nunez MR and Calvo L (2000). Effect of high temperature on seed germination of Pinus sylvestris and Pinus halepensis. Forest Ecology and Management, 131: 183-190.

Tabuna H (1999). Le Marché des Produits forestiers non Ligneux de l'Afrique Centrale en France et en Belgique. OCCASIONAL PAPER. Pp. 32.

Tsombou FM (2015). Les applications sylvicoles dans la régénération d'Aframomummelegueta dans les sols de trois forets sacrées de l'ouest Cameroun (Bamendjinda, Bamendjo et MbingMekoup). Thèse de Doctorat, Université de Dschang. 200p.

Wamegni J (1991). Etude de la phénologie, des fruits, des graines et de la germination de Fagara macrophylla. Mémoire d'Ingénieur des Eaux et Forêts à l'Université de Dschang. Pp. 50.

Yembi $\mathrm{P}$ (2000). Enquête préliminaire sur les produits forestiers non ligneux présents sur les marchés de Libreville (Gabon). (eds). Les produits forestiers non ligneux en Afrique recherches actuelles pour le développement Rome. Pp. 20. 